\title{
Early-life status epilepticus induces long-term deficits in anxiety and spatial learning in mice
}

\author{
Gregory Smith $^{\mathrm{a}}$, Nowrin Ahmed ${ }^{\mathrm{b}}$, Erin Arbuckle ${ }^{\mathrm{a}}$, Joaquin N. Lugo ${ }^{\mathrm{a}, \mathrm{b}, *}$ \\ a Institute of Biomedical Sciences, Baylor University, Waco, TX 76798, USA \\ ${ }^{\mathrm{b}}$ Department of Psychology and Neuroscience, Baylor University, Waco, TX 76798, USA
}

\section{A R T I C L E I N F O}

\section{Article history:}

Received 1 August 2016

Accepted 19 December 2016

Available online 9 January 2017

\section{Keywords:}

Anxiety

Behavior

Social behavior

Learning and memory

Early development

\begin{abstract}
A B S T R A C T
Background: One of the most devastating aspects of developmental epilepsy is the long-term impact on behavior. Children with epilepsy show a high co-morbidity with anxiety disorders and autism.

Methods: To examine whether early-life status epilepticus results in altered anxiety, repetitive behavior, social behavior, and learning and memory, we induced status epilepticus in male C57BL/6 mice on postnatal day (PD) 10 . The mice received intraperitoneal injections of either kainic acid $(2 \mathrm{mg} / \mathrm{kg}$ ) or $0.9 \%$ normal saline. We also included a nontreated control group. Kainic acid induced status epilepticus for approximately $1.5 \mathrm{~h}$. At PD60, the adult mice were then tested in a battery of behavioral tasks, including open field activity, elevated-plus maze, light-dark test, marble burying, social chamber, social partition, conditioned fear, novel object recognition, and Morris water maze.

Results: The early-life seizure group showed consistent increases in anxiety in the open field test $(p<0.05)$, elevated plus maze $(p<0.05)$, and light-dark task $(p<0.01)$. The seizure group showed significant $(p<0.01)$ impairment in the Morris water maze. There were no differences observed in marble burying, social partition, social chamber, novel object recognition, or delay fear conditioning tasks.

Conclusions: These results demonstrate that a single insult of status epilepticus during the neonatal period is sufficient to cause specific, long-term impairments in anxiety and spatial learning.

(c) 2016 Published by Elsevier, a division of RELX India, Pvt. Ltd on behalf of Indian Epilepsy Society.
\end{abstract}

\section{Introduction}

Approximately $0.5-1 \%$ of children ages $0-16$ are diagnosed with epilepsy. ${ }^{1}$ The highest incidence of seizures occurs during the first year of life, ${ }^{2}$ with prolonged seizures increasing overall seizure susceptibility in adolescence and adulthood. ${ }^{3}$ One life-threatening type of seizure condition is status epilepticus (SE), which is characterized as a series of acute, prolonged seizures. SE is primarily observed in children, ${ }^{4}$ but is also seen in the adult population. Although, the estimated mortality rate of SE is approximately $6-18 \%$, children show significantly greater recovery than adults. 5,6

Children experiencing SE during early life have been shown to exhibit long-term alterations in cognition and behavior, ${ }^{7,8}$ and impairments in intellectual functioning. ${ }^{79} \mathrm{Co}$-morbidity estimates between epilepsy and mood disorders, such as anxiety and depression, are approximately $50-60 \%$ of patients with epilepsy. ${ }^{10}$

\footnotetext{
* Corresponding author at: Baylor University,Department of Psychology and Neuroscience, One Bear Place \# 97334, Waco,TX, 76706, USA.

E-mail address: joaquin_lugo@baylor.edu (J.N. Lugo).
}

Further, mood disorders have a higher incidence rate in children with epilepsy than in children with any other long-term medical conditions. ${ }^{11}$ There is also evidence indicating a high comorbidity between autism and epilepsy, ${ }^{12-14}$ with approximately $30 \%$ of epileptic patients diagnosed with autism spectrum disorder. ${ }^{12}$ Therefore, understanding the relationship between epilepsy and the development of its associated disorders has potential to improve the lives of many children.

Studies using animal models of epilepsy have confirmed many of the observations from human studies. SE during early development does not commonly result in spontaneous seizures, unlike when induced in adult animals. ${ }^{15}$ There has also been less reported cell loss and synaptic alterations in animals with SE during early development than in adulthood. ${ }^{16}$ Although many previous studies have examined the effects of early-life SE on cognition and anxiety, when taken together the overall long-term behavioral impact remains unclear. There have been reports that early-life SE in rodent models result in long-term elevation in anxiety, ${ }^{17-22}$ while others have found no change in anxiety level. ${ }^{23,24}$ There have also been studies that observed spatial learning deficits, ${ }^{18,20-22}$ while others have found no deficits in 
spatial memory in rodents. ${ }^{16,23}$ Several studies have found that early-life SE and early-life flurothyl seizures result in long-term changes in social behavior. ${ }^{15,24,25}$

One common concern with many of these studies is the use of only a single test to examine behavioral phenotypes. In the current study, we investigated long-term changes in anxiety, repetitive behaviors, social behavior, and learning following early-life SE on postnatal day 10 . In order to improve the reliability of our results, as compared to previous studies, we included complementary measures for each behavioral phenotype. The results from this study could enhance our understanding of epilepsy, as well as provide strong foundations for future studies aiming to examine the cellular and molecular mechanisms for these deficiencies.

\section{Material and methods}

\subsection{Animals}

For the following studies we used C57BL/6J male mice. These mice were generated and housed at Baylor University at an ambient temperature of $22^{\circ} \mathrm{C}$, with a 14-h light and 10-h dark (20:00-6:00 h) diurnal cycle. The mice were given ad libitum access to food and water. All procedures to the animals were approved by the Baylor University Animal Care and Use Committee.

\subsection{Design}

On postnatal day (PD) 10, C57BL/6J pups received intraperitoneal injections of either $2 \mathrm{mg} / \mathrm{kg}(0.5 \mathrm{mg} / \mathrm{ml})$ dose of kainic acid (Tocris, Bristol, UK) solution or $0.9 \%$ normal saline. The animals were subsequently monitored and behavioral seizures were scored using a modified Racine scale. ${ }^{26}$ The seizure group experienced status epilepticus within thirty minutes of injection and continued for $1.5 \mathrm{~h}$. The vehicle mice received an injection of saline and were isolated from their mother for an equivalent period of time as the seizure mice. The non-treated control pups remained with their mother throughout this period. Behavioral testing began on approximately PD 60. Throughout all behavioral testing animals were first acclimated to the room for $30 \mathrm{~min}$. At the conclusion of each behavioral test we cleaned the behavioral apparatus with $30 \%$ isopropyl alcohol solution.

\subsection{Assessment of behavioral parameters}

\subsubsection{Open field activity}

The mice were placed into the clear acrylic arena $(40 \times 40 \times 30$ $\mathrm{cm}$ ) to investigate their activity and anxiety levels for $30 \mathrm{~min}$ using a computer-operated optical animal activity system (Fusion by AccuScan Instruments, Inc.; Columbus, USA). Total distance moved, distance in center, center time, activity count, and stereotypy count was measured. The sample size for the open field test was $n=17$ for the controls and $n=19$ for the SE group.

\subsubsection{Elevated plus maze}

We used the elevated plus maze to evaluate differences in anxiety. ${ }^{27}$ The apparatus consisted of two enclosed and two open horizontal perpendicular arms $(30 \times 5 \mathrm{~cm})$ positioned $40 \mathrm{~cm}$ above the floor with a central square platform $(5 \times 5 \mathrm{~cm})$ that forms from the connection of the four arms. We used video tracking software (Noldus: Ethovision; Netherlands) to score the time spent and frequency of visits in the open arms, center arms, and closed arms during a ten-minute test. We simultaneously video-recorded the test and later scored head-dips in the open arms and rearing in the closed arms manually. In the elevated plus maze video tracking data, the sample size for the control group was $n=15$ and for the SE group was $n=8$. For all data pertaining to the head dips and rearing $\mathrm{n}=11$ for the control group and $\mathrm{n}=8$ for the SE group.

\subsubsection{Light/dark test}

A separate cohort of mice was tested in the light/dark exploration test as an additional measure of anxiety. ${ }^{28}$ The mice were placed into a clear acrylic arena $(40 \times 40 \times 30 \mathrm{~cm})$ that was evenly divided into an open area and a black enclosed area in which the mice could freely enter and exit. Activity was collected by a computer-operated optical animal activity system (Fusion by AccuScan Instruments, Inc.; Columbus, USA). In the light/dark test the sample size for the control group was $n=7$ and for the SE group was $\mathrm{n}=10$.

\subsubsection{Marble burying}

The marble-burying test was used to examine repetitive behavior. The mice were placed in clean mouse cages $(27 \times 16.5 \times 12.5)$ with sanichip bedding that had 20 black glass marbles placed in an equidistant $4 \times 5$ pattern. The number of marbles buried $(>75 \%, 100 \%$, or completely covered by bedding material) was recorded. The sample size for the control group was $n=18$ and for the SE group was $n=19$ in the marble burying test.

\subsubsection{Social chamber test}

We used the three-chamber social behavior test to examine social behavior in mice using methods previously described. ${ }^{24}$ There were two ten-minute phases to this test. In the first phase the animal was placed in the apparatus and we recorded the time the animal spent in the left chamber, center, right chamber, and corner cups. For the second phase, we placed an unfamiliar C57BL/ 6J (gender-, age-, weight-matched) mouse under one of the corner cups and a similarly sized black Lego ${ }^{\circledR}$ block at the other corner cup. We recorded the time spent in each chamber and at the cups for the trial. All behavior was recorded using a digital video recording program (Dazzle DVD recorder, Pinnacle; Ottawa, Canada) and was scored later by an individual blind to the condition of the mouse. The control group sample size was $n=18$ and for the SE group was $n=19$.

\subsubsection{Social partition test}

We examined their behavior in the social partition test using methods previously described. ${ }^{29}$ For this test each experimental animal was housed with an unfamiliar C57BL/6J (sex-, age, weightmatched) mouse for $24 \mathrm{~h}$ in a standard cage. A clear perforated $(0.6 \mathrm{~cm}$-diameter holes) partition separated the mice. The first five minute test consisted of the time and frequency the animal spent with the familiar mouse. The mouse was then removed and an unfamiliar mouse C57BL/6J was placed in the previously vacant part of the partition. We then measured time and frequency of the visits of the experimental mouse to the partition. After the 5 min test we then reintroduced the familiar mouse (same mouse as in trial 1) and measured the time and frequency at the partition. In social partition test the control group was $n=18$ and the SE was group $n=19$.

\subsubsection{Morris water maze}

The Morris water maze (MWM) test was used to examine spatial learning and memory deficits as previously described. ${ }^{30}$ Mouse movement was monitored by a video camera connected to a computer with digital tracking software (Noldus Ethovision; Netherlands). The mice were tested for their ability to locate a submerged square platform $(14.5 \times 14.5 \mathrm{~cm})$. The mice were tested for 2 blocks per day for a total of 4 days. After the completion of the eighth block, each animal was given a probe trial for $60 \mathrm{~s}$. We conducted a visible platform test the following day to evaluate whether the mice had difficulty in locating a visible platform. In 
Morris water maze the sample size for the control group was $n=17$ and for the SE group was $n=19$.

\subsubsection{Novel object recognition}

We examined acute memory in the novel object recognition test using methods previously described. ${ }^{31}$ The subject was first placed in the testing chamber for $20 \mathrm{~min}$ in order to acclimate to the testing environment. On the following day the mice were introduced to the testing arena. During phase one there were two identical objects that were placed in the back corners of the arena. The subject was placed in the arena and allowed to examine the objects for $10 \mathrm{~min}$. The testing was video-recorded and scored later by an experimenter blind to the treatment of the mouse. One hour after the completion of phase one the animal was reintroduced to the testing chamber. In phase two we removed one of the objects, replaced it with a novel object, and recorded their behavior in the five minute trial. The sample size in the novel object recognition test was $n=17$ for the control group and $n=19$ for the SE group.

\subsubsection{Conditioned fear test}

A conditioned fear task was performed as previously described using the FreezeFrame monitoring system (Coulbourn; Holliston, USA). ${ }^{30}$ On the training day, mice were placed in the test chamber and allowed to explore for $2 \mathrm{~min}$. The conditioned stimulus (CS) was presented for $30 \mathrm{~s}$ (a white noise $80 \mathrm{~dB}$ sound) and followed immediately by a mild foot shock $(2 \mathrm{~s}, 0.7 \mathrm{~mA})$ that served as the unconditioned stimulus (US). After $2 \mathrm{~min}$, the mice received a second CS-US pairing. Mice were tested for cued fear responses $24 \mathrm{~h}$ after conditioning. The cued fear test involved testing the response of the mice to an auditory CS in a new environment. Mice were placed into this new chamber and freezing was recorded for $3 \mathrm{~min}$ in this new context. The auditory CS was then presented for $3 \mathrm{~min}$ and freezing was recorded. The sample size in the fear condition test for the control group was $n=7$ and for the SE group was $n=10$.

\subsection{Statistical analysis}

All data were analyzed by using SPSS 20.0 for PC (SPSS; Chicago, USA) or by Graphpad Prism 6 for PC (San Diego, USA). For all comparisons, the level of significance was set at $\mathrm{p}<0.05$. For all analyses, controls and handled controls were combined since no statistically significant differences were found between the groups. Animals were monitored for normal weight gain and no significant differences were found between groups.
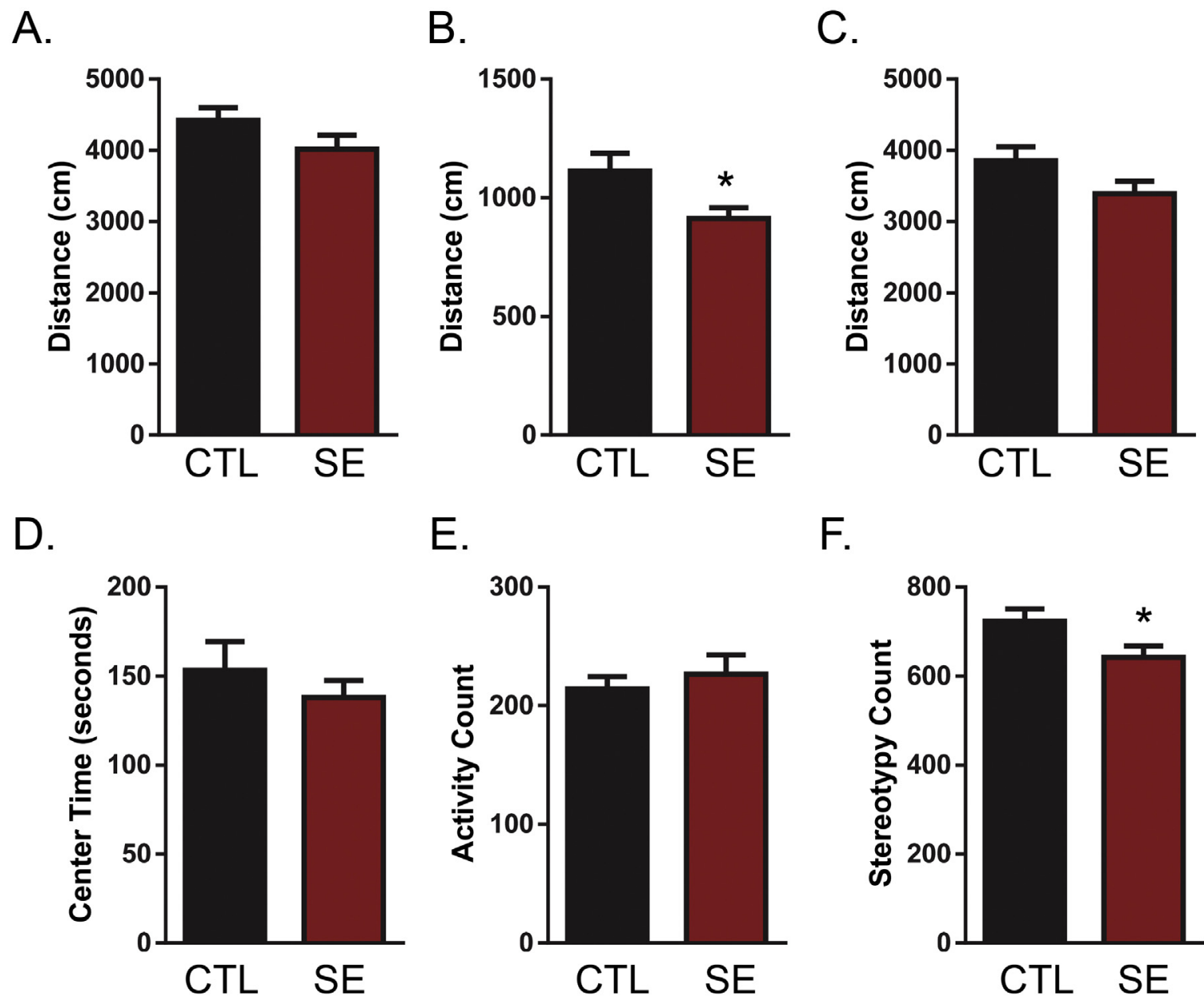

F.

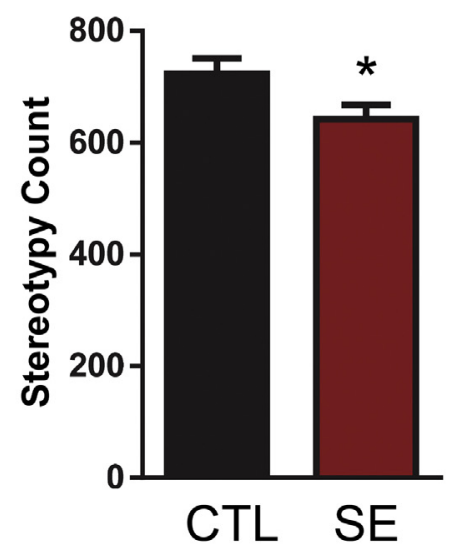

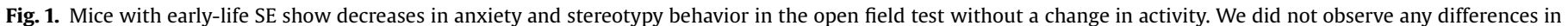

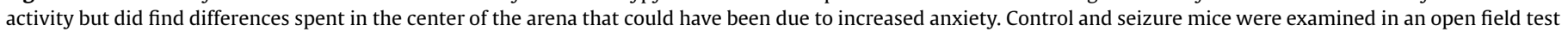

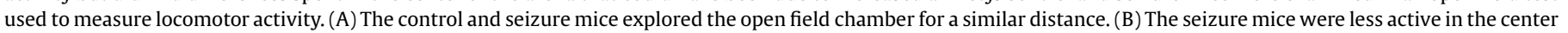

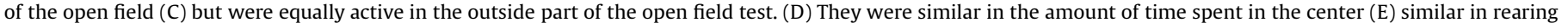

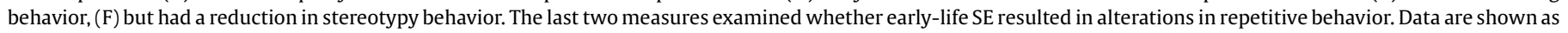
mean \pm standard error of the mean; $n=17$ control; $n=19$ seizure. ${ }^{*}=p<0.05$. 


\section{Results}

\subsection{Results of behavioral parameters}

3.1.1. Mice with early-life SE show increased anxiety and decreased stereotypy behavior in the open field test, without changes in overall activity levels

We first examined whether early-life SE impacted activity levels and anxiety behavior by using an open field test. The control and seizure mice showed no difference in total activity $[t(1,34)=1.52$, $\mathrm{p}=0.14$ ] (Fig. 1A). However, there were significant differences in the center distance explored $[t(1,34)=2.31, p<0.05]$ (Fig. 1B). The early-life SE group spent less time in the center, indicating an increase in anxiety in the open field test. There were no differences in distance in the surround area $[(1,34)=1.76, p=0.08]$ (Fig. $1 \mathrm{C}$ ), in the time spent in the center of the open field $[t(1,34)=0.83$, $\mathrm{p}=0.41]$ (Fig. 1D). There were no differences in rearings/vertical count $[(1,34)=0.63,=0.53]$ (Fig. 1E). However, the early-life SE group did spend less time performing stereotypy behavior (selfgrooming), as compared to the control group $[t(1,34)=2.18$, $\mathrm{p}<0.05$ ] (Fig. 1F). There were no differences in weight $\mathrm{t}(1$, $34)=0.5, p=0.65$ between the control $24.9 \mathrm{~g} \pm 0.4$ compared to seizure mice $24.6 \mathrm{~g} \pm 0.4$ at the time of the open field testing.

3.1.2. Mice with early-life SE show increased anxiety in the light/dark test and elevated plus maze test

We next examined whether early-life SE impacted anxiety behavior using the light/dark test. There was a significant
A.

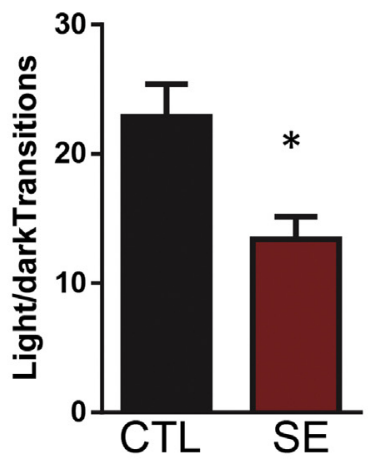

C.

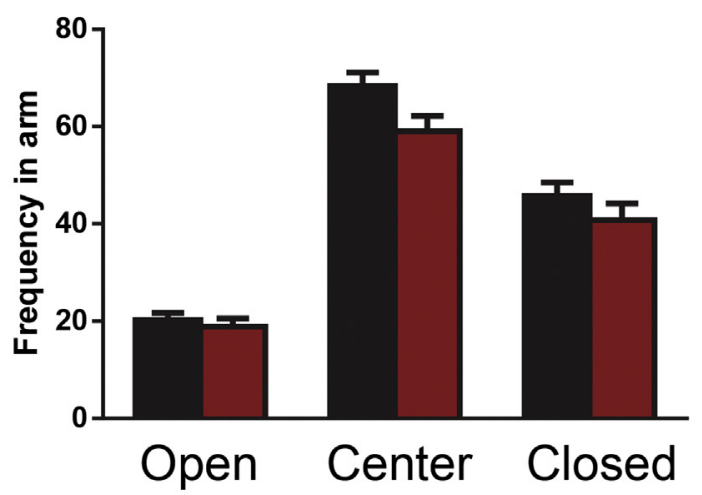

B.

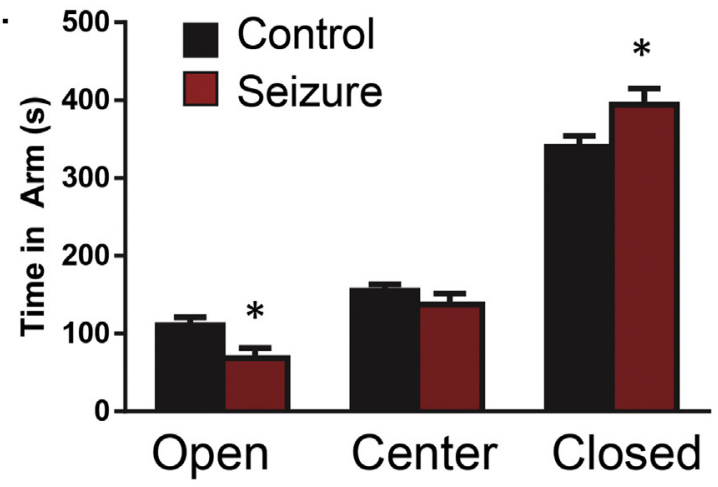

D.

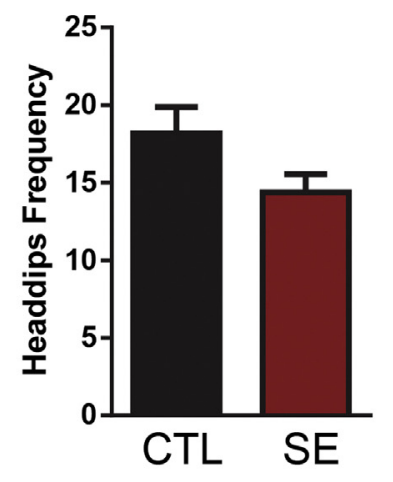

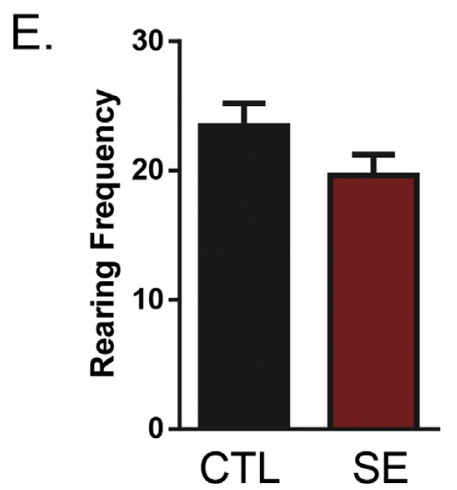

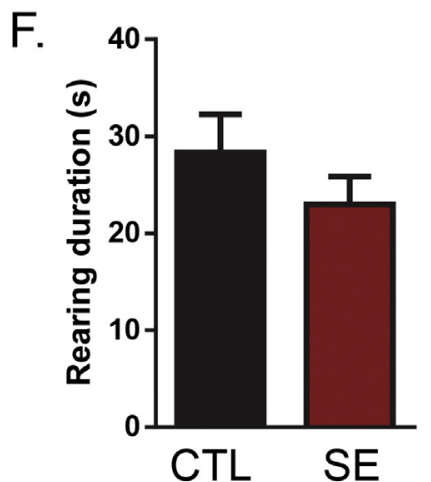

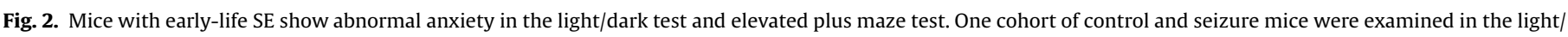

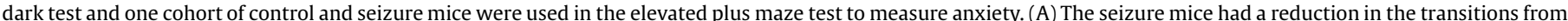

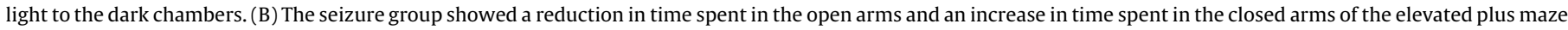

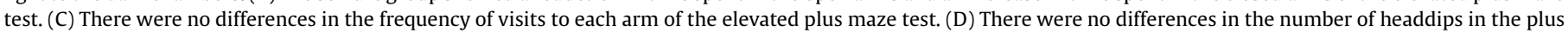

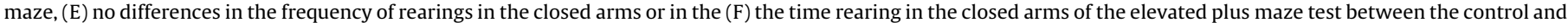

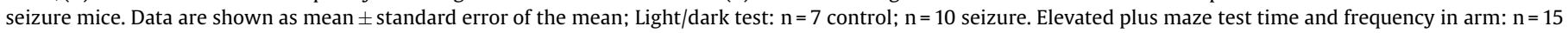
control; $\mathrm{n}=8$ seizure. Elevated plus maze test headdips and rearings: $\mathrm{n}=11$ control; $\mathrm{n}=8$ seizure. ${ }^{*}=\mathrm{p}<0.05$. 
difference in the number of transitions $[t(1,15)=3.18, p<0.01]$ (Fig. 2A) with SE group mice exhibiting fewer transitions between the light and dark compartments. The decrease in transitions indicates that the early-life SE mice were more anxious in the light/ dark test.

In the elevated-plus maze, the early-life SE group mice spent less time in the open arms $[\mathrm{t}(1,21)=2.47, \mathrm{p}<0.05]$ (left 2 graphs for Fig. 2B); no difference in the center time $[t(1,21)=1.23, p=0.23$ ] (center graphs for Fig. 2B); and spent more time in the closed arms $\mathrm{t}(1,21)=2.19, \mathrm{p}<0.05$ (Fig. 2B right 2 graphs for Fig. 2B). There were no significant differences in the frequency of visits to the open, center, or closed arms between the control and early-life SE group (Fig. 2C). The decrease time spent in the open arms and increased time spent in the closed arms observed in the early-life SE group indicates an increase in anxiety behavior. There were no differences between groups observed in head dips in the open arms $[t(1,21)=1.71, p=0.10]$ (Fig. 2D), in the frequency of rearings in the closed arms $[\mathrm{t}(1,21)=1.54, \mathrm{p}=0.14]$ (Fig. 2E), or rearing duration $[\mathrm{t}(1,21)=1.0, \mathrm{p}=0.33]$ (Fig. $2 \mathrm{~F}$ ). The light/dark test and elevated plus maze test complemented the results in the open field test, indicating that mice following early-life SE have a long-lasting increase in anxiety behavior.
3.1.3. Mice with early-life SE show no change in repetitive behavior in the marble-burying test

We next examined whether early-life SE impacted repetitive behavior using the marble-burying test. At the conclusion of the $30 \mathrm{~min}$ trial we removed the mice and counted the number of marbles buried (out of 20 ) at the $75 \%$ level, $100 \%$ level, or completely buried. We used several measures to determine if one measure was more sensitive than another. There were no significant differences between groups in the number of marbles buried at the $75 \%$ : [control $=14.9 \pm 0.7$; early-life $S E=13.9 \pm 0.9$ ]; at $100 \%$ : [control $=12.1 \pm 0.7$; early-life $\mathrm{SE}=11.8 \pm 0.9$ ]; or completely buried: [control $=8.6 \pm 0.8$; early-life $\mathrm{SE}=9.4 \pm 0.9$ ]. The values represent the number of marbles buried (out of 20) in the $30 \mathrm{~min}$ trial. These results indicate that early-life SE does not have longlasting impact on repetitive behavior.

\subsubsection{Mice with early-life SE show normal social behavior in the social chamber and social partition tests}

We next examined whether early-life SE impacted social behavior using the social chamber and social partition tests. We found that early-life SE did not change the preference for a novel animal compared to a novel object. There were no differences between the groups in terms of preference for the novel animal [ $\mathrm{t}$
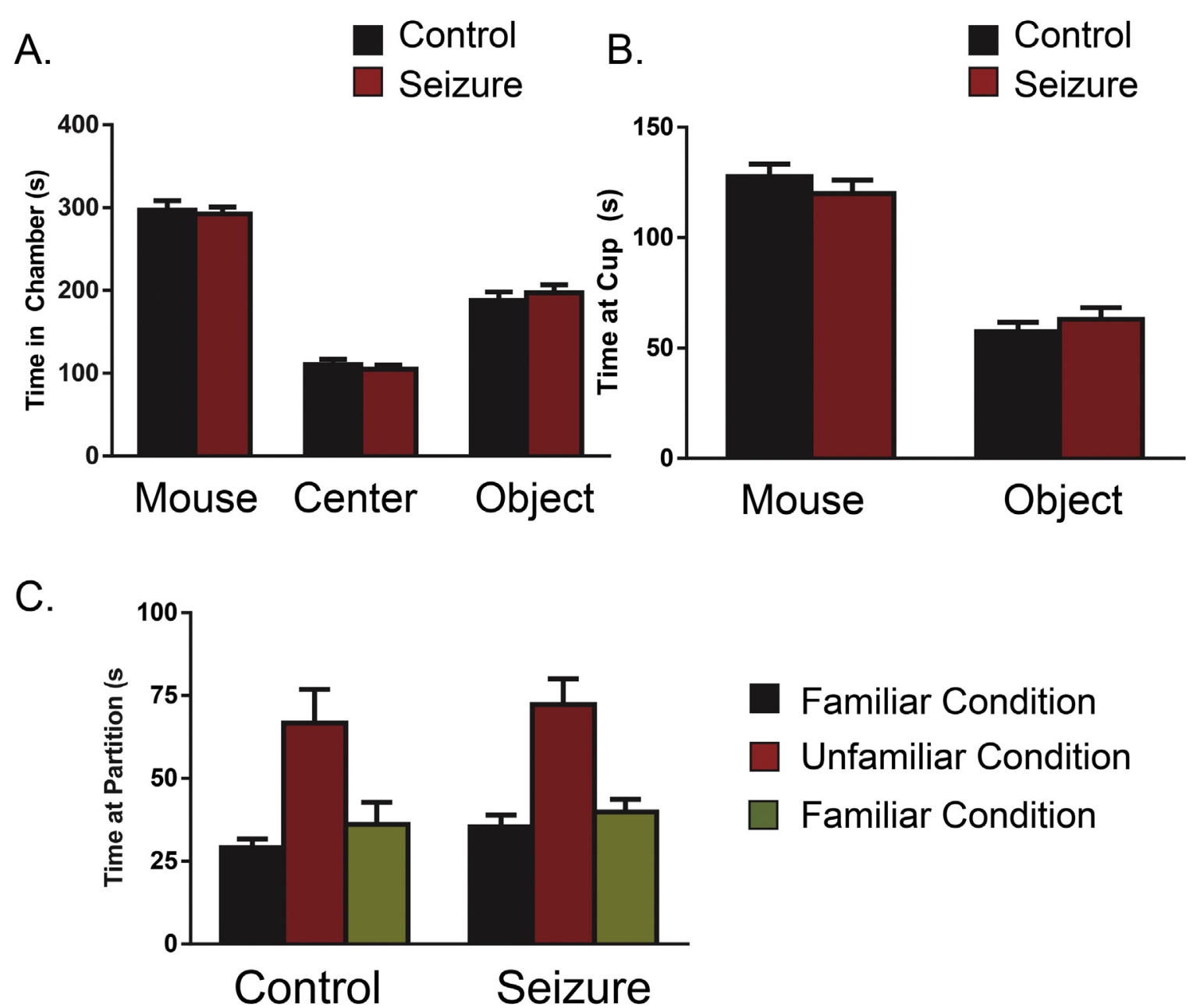

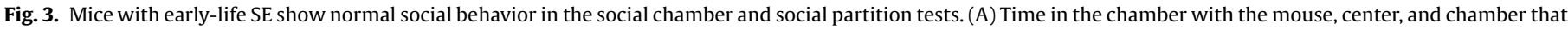

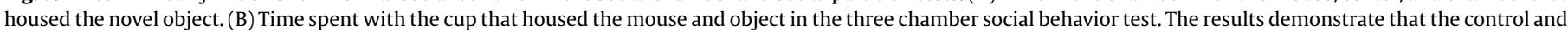

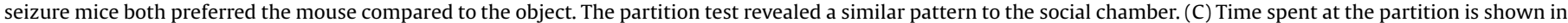

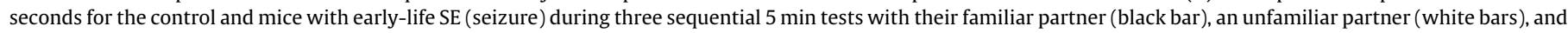
back to familiar partner (gray bar). The values represent the mean \pm SEM. $n=18$ control; $n=19$ seizure. 
$(1,35)=0.34, \mathrm{p}=0.74]$; center $[\mathrm{t}(1,35)=0.7, \mathrm{p}=0.5]$; or novel object $[t(1,35)=0.65, p=0.52]$ (Fig. 3A). There were no differences between the groups in terms of preference for a novel animal at the cup $[\mathrm{t}(1,35)=0.9, \mathrm{p}=0.36]$ or at the cup with the novel object [ $\mathrm{t}$ $(1,35)=0.82, p=0.41]$ (Fig. 3B). The control mice had a significant preference for the chamber that housed the novel mouse $[t(1,17)=5.35, p<0.001]$ and so did the early-life SE group $[t(1,18)=5.4, p<0.001]$ (Fig. 3A). A similar preference was found for the duration of time the experimental animal spent at the cup that housed the novel mouse for both the control mice [ $t$ $(1,17)=9.8, \mathrm{p}<0.001]$; and the early-life SE mice $[\mathrm{t}(1,18)=8.3$, $\mathrm{p}<0.001$ ] (Fig. 3B). We also ran a mixed ANOVA and found no main effect of group over the three testing conditions $[F(1,35)=0.57$, $\mathrm{p}=0.50]$. However, there was a main effect across the 3 conditions $[F(2,68)=32.4, p<0.001]$ but no interaction between testing conditions and group $[F(2,68)=0.03, p=0.97]$. These results indicate that early-life SE does not have long-lasting impact on social behavior.

\subsubsection{Mice with early-life SE show impairment in spatial learning and memory}

We next examined whether early-life SE impacted hippocampus-dependent behavior using the MWM test. Mice with early-life SE showed a significant decrease in their ability to learn to find the

A.

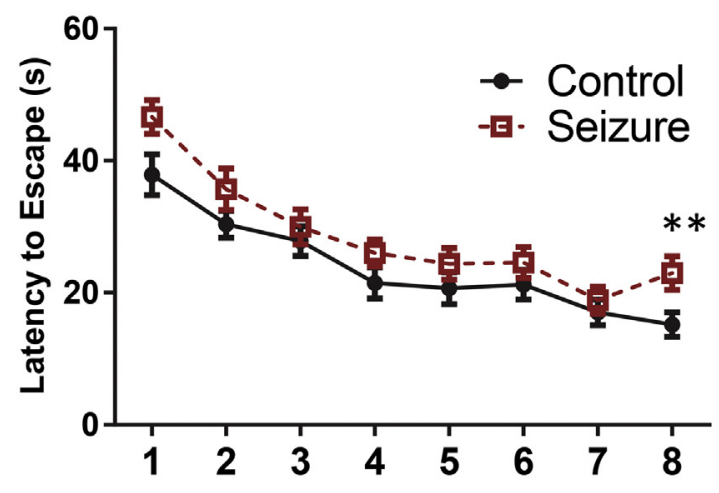

B.

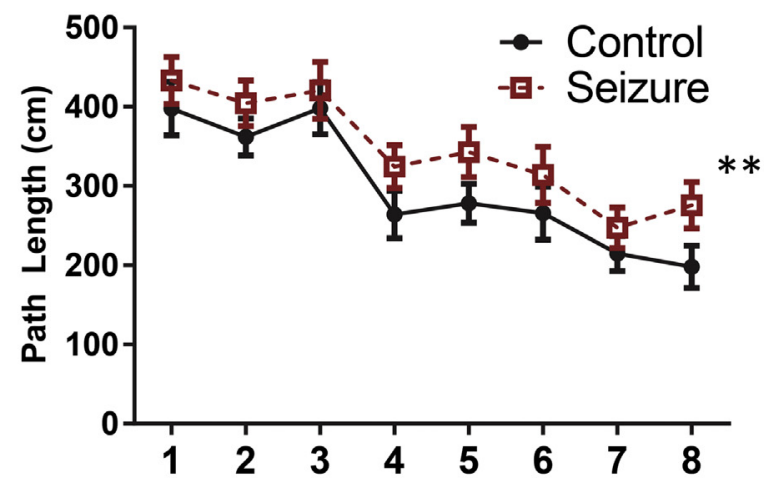

C.

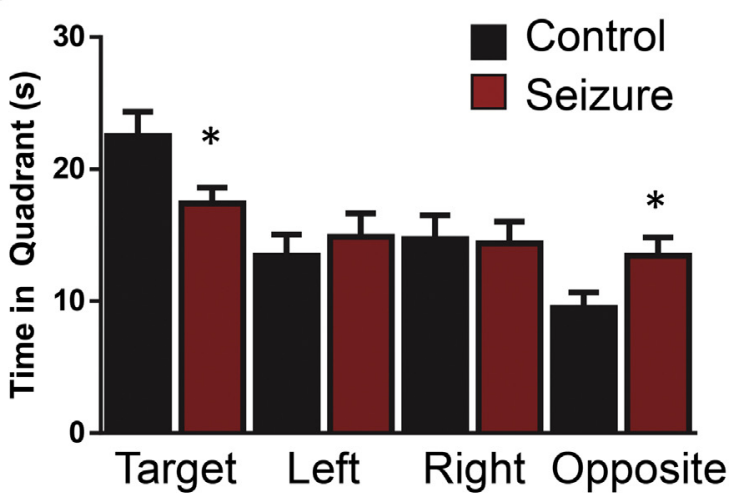

D.

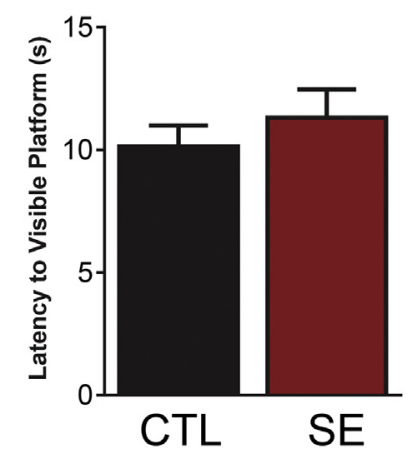

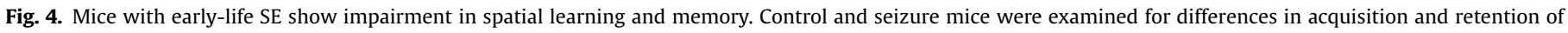

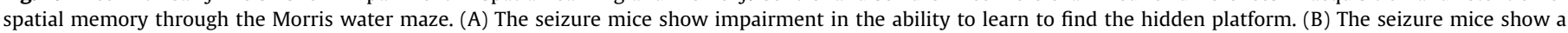

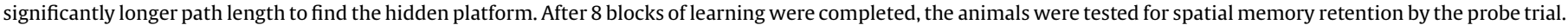

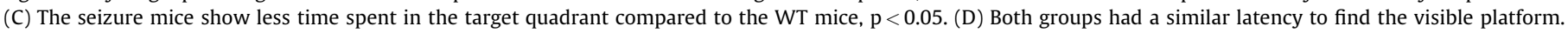
${ }^{* *}=\mathrm{p}<0.01 . \mathrm{n}=17$ control; $\mathrm{n}=19$ seizure. 
hidden platform compared to controls with a main effect across all trials $[\mathrm{F}(1,34)=8.88, \mathrm{p}<0.01]$ (Fig. 4A). A main effect of block was also found $[F(1,34)=92.1, p<0.001]$, but no interaction between block and group was found $F(1,34)=0.16, p=0.69$. In addition, mice with early-life SE also had a significantly longer path length than controls across all trials $[F(1,34)=7.2, p=0.01]$ (Fig. 4B).

We then examined spatial memory in a probe trial. We found that mice with early-life SE showed a significant decrease in the time spent in the target quadrant during the probe trial (Fig. 4C). We did not find an overall group effect $[F(1,34)=0.9, p=0.344]$, but we did find a group by quadrant interaction $[F(1,34)=5.2, p<0.05]$. Individual $t$-tests revealed a significant difference between the early-life SE and control groups in the amount of time spent in the target region $[\mathrm{t}(1,34)=2.3, \mathrm{p}<0.05]$ and for the opposite quadrant $[\mathrm{t}(1,34)=2.1, \mathrm{p}<0.05]$. We observed no differences in the time to find the visible platform $[t(1,34)=0.60, p=0.55]$ (Fig. 4D). These results indicate that early-life SE has a long-lasting impact on spatial learning.

3.1.6. Mice with early-life SE do not show impairment in the novel object recognition test or delay fear conditioning

We then examined whether early-life SE affected recognition memory and fear memory by using the novel object recognition and delayed fear conditioning tests. There was no preference difference to the left or right object within the control group [ $\mathrm{t}$ $(1,16)=1.27, p=0.2]$; or early-life $S E$ group $[t(1,17)=0.4, p=0.68]$, or when compared to each other (Fig. 5A). Both sets showed significant preference for the novel object compared to the familiar object: Control $[\mathrm{t}(1,16)=7.4, \mathrm{p}<0.0001]$; early-life SE [t $(1,17)=6.9, \mathrm{p}<0.0001$ ] (Fig. $5 \mathrm{~B}$ ). However, there were no differences in preference between the groups in the novel object condition $[\mathrm{t}(1,34)=0.42, \mathrm{p}=0.67]$ (Fig. 5B).
A.

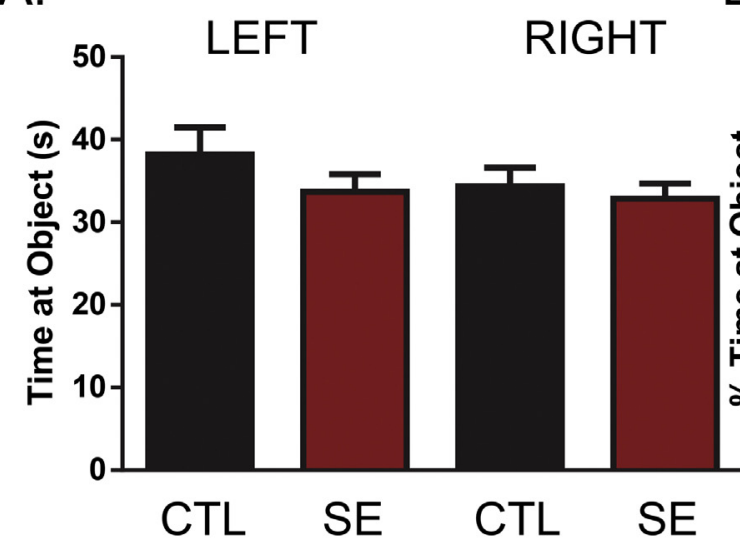

C.

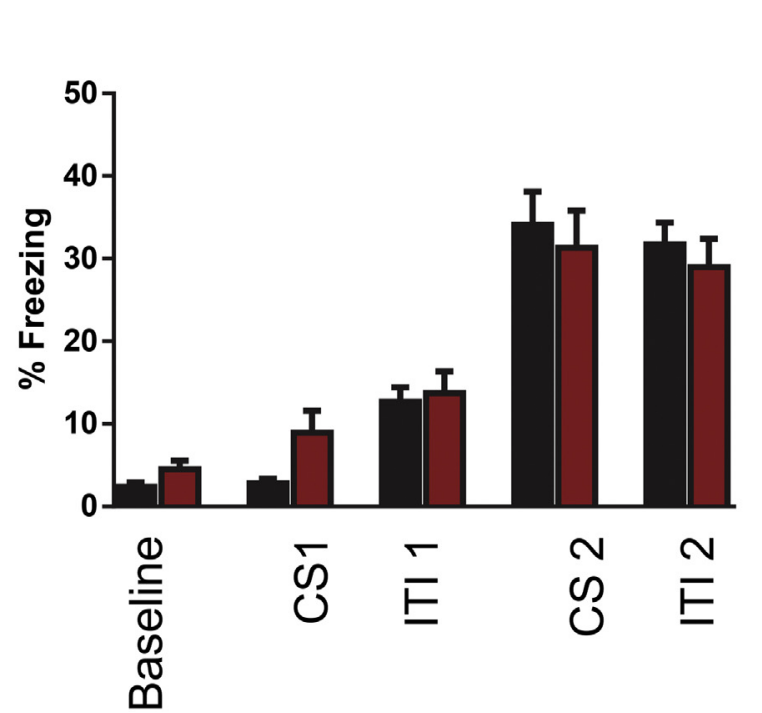

B.

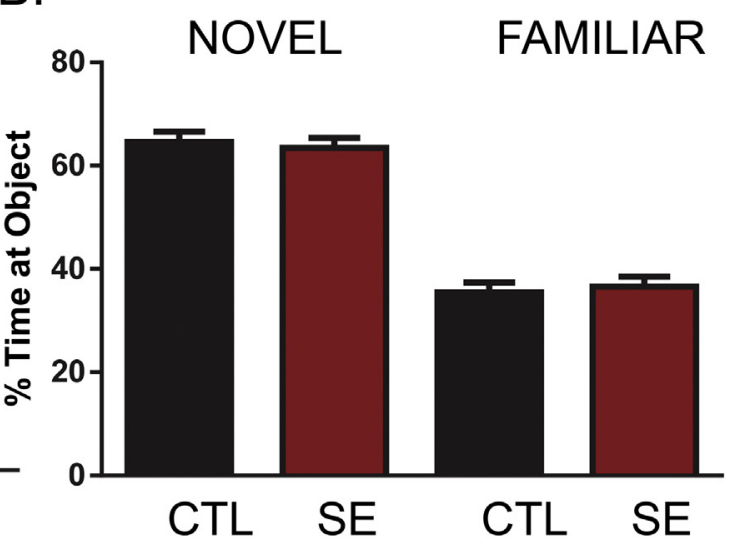

D.

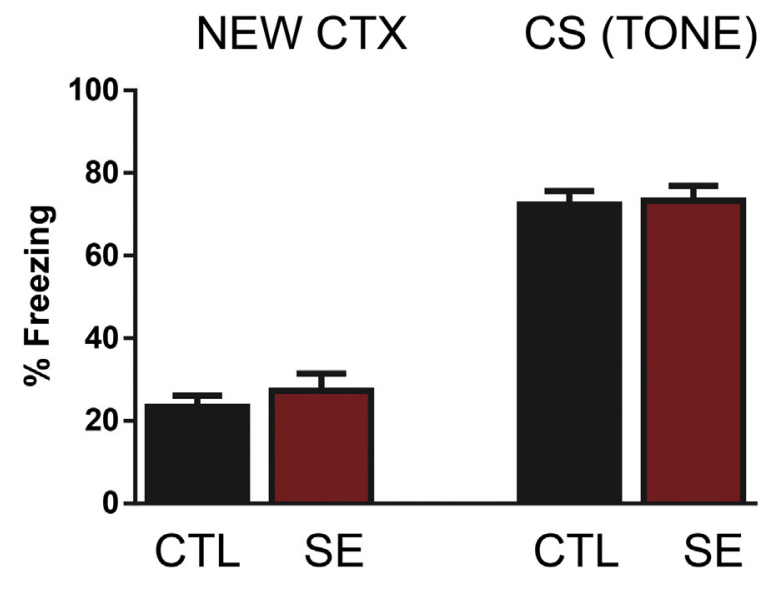

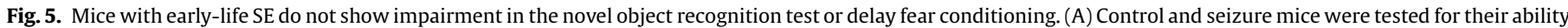

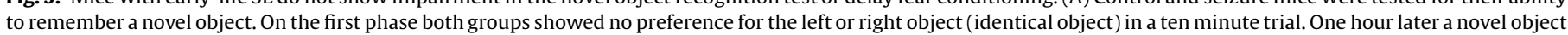

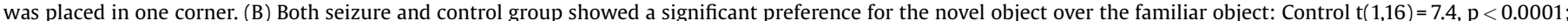

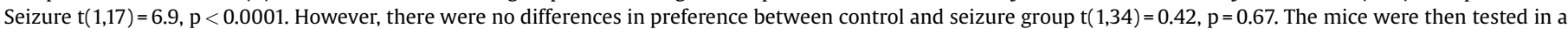

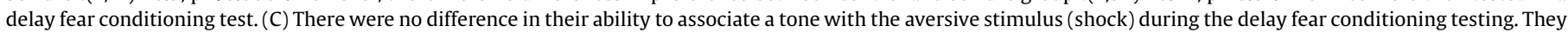

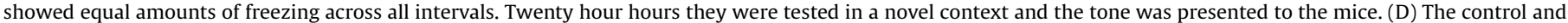

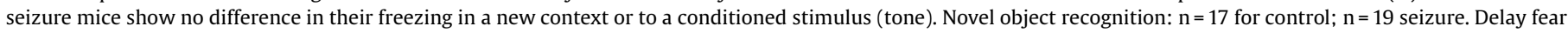
conditioning: $n=7$; seizure $=10$. Data are shown as mean $\pm S E M ;{ }^{*}=p<0.05 ;{ }^{* *}=p<0.01$. 
We then measured ability to form associations between the testing context and a tone for fear conditioning. We found no difference between the groups on the training day $[F(1,15)=0.107$, $\mathrm{p}=0.748$ ]. However, both groups did show an increase in freezing over the different periods of training $[F(4,60)=49.4, p<0.001]$ (Fig. 5C). There was no interaction between group across the periods $[F(4,60)=0.92, p=0.47]$. We found no difference between the groups in the new context or when the tone was presented (Fig. 5D). The control and early-life SE mice were not different in their freezing for a new context $[t(1,15)=0.70, p=0.5]$, or to the tone CS: $[t(1,15)=0.17, p=0.86]$. These results indicate that earlylife SE does not have a long-lasting impact on novel object recognition and conditioned fear (Table 1 ).

\section{Discussion}

The results of the present study demonstrate that a single insult of SE during early life can lead to specific long-term impairments in anxiety and spatial learning behaviors. We found a reduction in the time spent in the center of the open field and a reduction in the number of transitions in the light/dark test. In a separate test that is commonly used to measure anxiety in mice, we found a reduction in the time spent in the open arms and an increase in the time spent in the closed arms of the test. Our finding that early-life SE cause long-term increases in anxiety corroborates the results of previous studies. ${ }^{19,22}$ In the Sayin et al. study, the authors induced SE in rats on PD 1, 7, 14, or 24 and reported significant reductions in time spent in the open arms over the closed arms across all time points. However, PD 24 was the only time point with a significant change in the number of head dips. In Moreira et al. experimenters used kainic acid to induce SE in PD 7 rats, and reported increased anxiety in adulthood.

There is increasing awareness in the clinical community that anxiety is one of the major psychiatric correlates of epilepsy. Studies suggest that within one year after being diagnosed with epilepsy, approximately $25 \%$ of patients will subsequently be diagnosed with an anxiety disorder. ${ }^{32}$ In some settings, the incidence rate of an anxiety disorder in this population has been reported to be greater than $50 \% .{ }^{33,34}$ Not all studies have observed a change in anxiety after early-life SE. One study induced SE on PD 7 in male Wistar rats and found change in anxiety. ${ }^{23}$ In the plus maze test, these authors report a slight reduction in the ratio of time spent in the open arms over the total time in all arms, but the effect was not statistically significant. One reason for the conflicting results may be due to the effect of repeated testing. In the Cornejo et al. study, authors examined animal behavior in many other behavioral tests. Anxiety tests in their study were also presented after several other behavioral tests. The effect of additional testing may have partially reduced the sensitivity of the elevated plus

Table 1

Review of behavioral changes after early-life status epilepticus.

\begin{tabular}{lll}
\hline Behavioral Phenotypes & Test & Change \\
\hline Anxiety & Open Field & $\uparrow$ \\
& Light/Dark & $\uparrow$ \\
& EPM & $\uparrow$ \\
& Marble Burying & None \\
Repetitive Behavior & Social Partition & None \\
Social Behavior & Social Chamber & None \\
& & \\
Learning \& Memory & MWM & $\downarrow$ \\
& Novel Object & None \\
& Fear Conditioning & None \\
\hline
\end{tabular}

maze test, as repeated testing is to known to temporarily affect performance in this test. ${ }^{35}$ Different strains of mice have been shown to habituate differently when repeatedly tested on anxiety related behavior. ${ }^{36}$ Given this impact of repeated testing in the measurement of anxiety, we split one cohort of animals to be tested in the light/dark test and another to be tested in the elevated plus-maze test following open field testing. Each cohort of the early-life SE group showed increased anxiety in the test they were examined in. Other possible factors that could have effected longterm changes in anxiety are seizure frequency or severity related to differences in kainic acid dosage. ${ }^{37}$ In addition, the animal species and postnatal time point of seizure induction were different between studies.

Due to increasing evidence of the comorbidity between epilepsy and autism, we examined social and repetitive behavior in mice across several behavioral tests. We first examined repetitive behavior through the open field test, and observed specific decreases in stereotypy count behavior in the early-life SE mice. The stereotypy measure through the automated software is believed to measure the repeated breaking of photobeams that is similar to self-grooming. We have not confirmed this association in our lab so we then examined the mice in the marble-burying test to more specifically measure repetitive behavior. There were no difference in the number of marbles buried at $75 \%, 100 \%$ or when completely buried. This is in contrast to a recent study where investigators administered kainic acid to PD 7 rats. ${ }^{25}$ These authors found a significant decrease in marble burying and an increase in side to side head movements but no difference in self-grooming. Some differences between this study and our study could be attributed to differences in the animal species used and the postnatal time point chosen for seizure induction. Future studies could include the nose poke test, nestlet shredding behavior, and a grooming analysis test to further examine differences in repetitive behavior. Future studies could also include video recording of the behaviors to determine the frequency in which the mice rebury the marbles in the 30 min test.

We then used the social chamber and social partition test to determine whether early-life SE resulted in social behavior deficits. We used a large sample size of 18-19 per group and found no differences in social behavior in either test. The social chamber test was used to determine the difference in preference for a novel object and a novel mouse. There was a clear preference for the novel mouse compared to the novel object, but there was no difference in the preference for the mouse between the control and seizure group. The social partition behavior was used to compare the preference of the experimental groups to familiar and non-familiar mice. The strength of this test is the repeatedmeasures aspect of the test that allows for the experimenter to determine the baseline social preference for each mouse and the difference in social interaction when presented with an unfamiliar and familiar mouse. We found no difference between the control and seizure group in the preference of the familiar and non-familiar mouse. We were surprised by the results in the social behavioral test, as we recently published a paper reporting that flurothyl seizures across postnatal days 7-11 result in social behavior deficits in social chamber and social partition tests. ${ }^{24}$ Other groups have also reported that early-life seizures can result in social behavior deficits. ${ }^{17,25,38}$ There is increasing awareness that early-life seizures are correlated with later alterations in social behavior. It is difficult to reconcile that while some groups, including our own, found deficits in social behavior, others found no deficits. There are differences in rat vs. mouse, seizure induction method used, and timing of the seizure induction. Given the new awareness of autistic-like phenotypes arising after seizures, future studies could compare the effects of different seizure induction methods, timing, strain, and species of 
experimental animal. The relationship between early-life seizures and autism is approximately $30 \%{ }^{39,40}$ For this reason, observing social behavior deficits should not be expected in all studies that examine the behavioral effects of early-life seizures.

Previous studies provide evidence that the hippocampus is especially sensitive to early-life seizures. One study found that hippocampal place cell abnormalities lead to impaired spatial memory. ${ }^{41}$ A separate study demonstrates that early-life hyperthermic seizures lowered inhibition in the CA1 hippocampal dendrites, and suggests that the behavioral deficits are caused by a loss of CA1 apical dendritic inhibition. ${ }^{42}$ It has also been shown that spatial memory formation by direct excitation of entorhinal to CA1 distal dendrites may be disrupted due to lowered inhibitory regulation. Repeated administration of flurothyl seizures during early development results in immature dendritic fields in pyramidal neurons within the CA1 region of the hippocampus. ${ }^{43}$ We used the MWM to determine whether the control and seizure mice had spatial learning and memory deficits. During the acquisition phase ( 8 trials) we found that the seizure mice had a longer latency to find the hidden platform and took a longer path length to find the hidden platform. The path length measure is important since the speed of the animal could confound the latency measure. The path length is a clearer measure of the spatial learning deficit. The probe trial also revealed that the seizure mice spent an equal amount of time in the four quadrants of the maze. The control group had a clear preference for quadrant that previously housed the target platform compared to the seizure group. Our study provides additional behavioral evidence that spatial learning is impacted by a single episode of neonatal seizures. One future direction for our studied would be to include EEG recording to determine whether the mice have abnormal epileptiform activity in the hippocampus. Interictal spikes or other abnormal EEG activity may impair learning and memory during adulthood.

One area we attempted to build on with our study was examining other types of learning and memory. Recognition memory, as tested by the Novel Object Recognition test, was found to be unimpaired and corroborates with a previous study that found no differences in recognition memory between control mice and seizure induced mice. ${ }^{23}$ This test examines the preference of the subject to a familiar and novel object. Novel object recognition is believed to engage the perirhinal cortex and lesions in the hippocampus do not affect novel object recognition. ${ }^{44}$ Therefore, SE may not affect the perirhinal cortex in early development. We also did not find any deficiencies in amygdala-dependent contextual fear memory, which corroborates with findings from a study by Cornejo et al. that investigates the developing brain of rats following early-life seizures. The fear conditioning test examines the ability of the subject to associate an aversive stimulus with a tone. The results from learning phase of the test demonstrate that the control and seizure mice freeze an equal amount to the baseline condition and to the presentation of the tones. We then tested the subject's ability to associate the aversive classical conditioning test the following day. The control and seizure mice had similar levels of freezing to the new context and when the tone was presented. There was a clear increase in freezing to the tone compared to the new context. One limitation of delay fear conditioning test is that it only examines amygdaladependent memory. Future studies could examine novel place recognition test or trace fear conditioning, which is a more hippocampal dependent learning and memory test.

The elevated anxiety levels observed in our study demonstrate a strong relationship between seizures and anxiety. This relationship is significant because it supports the claim that there is a bidirectional relationship between mood disorders and epilepsy, and that behavioral deficits are not a result of only psychiatric conditions. ${ }^{11}$ Anxiety and its associated mood disorders, such as depression, are often left undiagnosed and untreated in patients with epilepsy. This situation can severely hamper the quality of life of epilepsy patients. ${ }^{45}$ This study suggests that increased anxiety and impaired spatial learning are co-morbidities of epilepsy. Further studies seek to understand the shared underlying circuitry between seizures and anxiety disorders. Moreover, the therapeutic benefit of anxiolytics on patients with epilepsy to help mitigate increased anxiety levels may also be investigated.

\section{Conclusion}

We found that a single insult of SE in C57BL/6J male mice during early life can cause a long-lasting increase in anxiety and impair spatial memory. Our study further suggests that spatial memory impairment is limited to selective disruption to the hippocampus.

\section{Conflict of interest}

The authors have none to declare.

\section{Acknowledgements}

This research was supported by funding from the Epilepsy Foundation, Baylor Young Investigator Research Program, and from NIH NINDS NS088776. We would like to thank Andrew Holley and Conner Reynolds for their critical review of the paper, and Dr. Brad Keele for the use of his Noldus Ethovision software for this project.

\section{References}

1. Camfield CS, Camfield PR, Gordon K, Wirrell E, Dooley JM. Incidence of epilepsy in childhood and adolescence: a population-based study in Nova Scotia from 1977 to 1985 . Epilepsia 1996:37:19-23.

2. Holmes GL, Ben-Ari Y. The neurobiology and consequences of epilepsy in the developing brain. Pediatr Res. 2001;49:320-325.

3. Koh S, Storey TW, Santos TC, Mian AY, Cole AJ. Early-life seizures in rats increase susceptibility to seizure-induced brain injury in adulthood. Neurology. 1999;53:915-921.

4. Gross-Tsur V, Shinnar S. Convulsive status epilepticus in children. Epilepsia. 1993:34(Suppl. 1):S12-20.

5. Aicardi J, Chevrie JJ. Convulsive status epilepticus in infants and children. A study of 239 cases. Epilepsia. 1970;11:187-197.

6. Matsumoto A, Watanabe K, Sugiura M, Negoro T, Takaesu E, Iwase K. Long-term prognosis of convulsive disorders in the first year of life: mental and physical development and seizure persistence. Epilepsia. 1983;24:321-329.

7. Baxendale S, Heaney D, Thompson PJ, Duncan JS. Cognitive consequences of childhood-onset temporal lobe epilepsy across the adult lifespan. Neurology. 2010;75:705-711.

8. Berg AT. Epilepsy, cognition, and behavior: the clinical picture. Epilepsia. 2011;52(Suppl. 1):7-12.

9. Nolan MA, Redoblado MA, Lah S, et al. Intelligence in childhood epilepsy syndromes. Epilepsy Res. 2003;53:139-150.

10. Beyenburg S, Mitchell AJ, Schmidt D, Elger CE, Reuber M. Anxiety in patients with epilepsy: systematic review and suggestions for clinical management. Epilepsy Behav. 2005;7:161-171.

11. Reilly C, Agnew R, Neville BG. Depression and anxiety in childhood epilepsy: a review. Seizure. 2011:20:589-597.

12. Clarke DF, Roberts W, Daraksan M, et al. The prevalence of autistic spectrum disorder in children surveyed in a tertiary care epilepsy clinic. Epilepsia. 2005;46:1970-1977.

13. Meidenbauer JJ, Mantis JG, Seyfried TN. The EL mouse: a natural model of autism and epilepsy. Epilepsia. 2011;.

14. Niemeyer MI, Cid LP, Sepúlveda FV, Blanz J, Auberson M, Jentsch TJ. No evidence for a role of CLCN2 variants in idiopathic generalized epilepsy. Nat Genet. 2010:12:3.

15. Bernard PB, Castano AM, O'Leary H, Simpson K, Browning MD, Benke TA Phosphorylation of FMRP and alterations of FMRP complex underlie enhanced mLTD in adult rats triggered by early life seizures. Neurobiol Dis. 2013;

16. Cornejo BJ, Mesches MH, Coultrap S, Browning MD, Benke TA. A single episode of neonatal seizures permanently alters glutamatergic synapses. Ann Neurol. 2007;61:411-426.

17. Castelhano AS, Cassane Gdos S, Scorza FA, Cysneiros RM. Altered anxietyrelated and abnormal social behaviors in rats exposed to early life seizures. Front Behav Neurosci. 2013;7:36. 
18. Holmes GL, Gairsa JL, Chevassus-Au-Louis N, Ben-Ari Y. Consequences of neonatal seizures in the rat: morphological and behavioral effects. Ann Neurol. 1998;44:845-857.

19. Moreira JD, de Siqueira LV, Lague VM, Porciuncula LO, Vinade L, Souza DO. Short-term alterations in hippocampal glutamate transport system caused by one-single neonatal seizure episode: implications on behavioral performance in adulthood. Neurochem Int. 2011;59:217-223.

20. Muller CJ, Bankstahl M, Groticke I, Loscher W. Pilocarpine vs lithiumpilocarpine for induction of status epilepticus in mice: development of spontaneous seizures, behavioral alterations and neuronal damage. Eur J Pharmacol. 2009;619:15-24.

21. Muller CJ, Groticke I, Bankstahl M, Loscher W. Behavioral and cognitive alterations, spontaneous seizures, and neuropathology developing after a pilocarpine-induced status epilepticus in C57BL/6 mice. Exp Neurol. 2009;219:284-297.

22. Sayin U, Sutula TP, Stafstrom CE. Seizures in the developing brain cause adverse long-term effects on spatial learning and anxiety. Epilepsia. 2004;45:1539-1548.

23. Cornejo BJ, Mesches MH, Benke TA. A single early-life seizure impairs shortterm memory but does not alter spatial learning, recognition memory, or anxiety. Epilepsy Behav. 2008;13:585-592.

24. Lugo JN, Swann JW, Anderson AE. Early-life seizures result in deficits in social behavior and learning. Exp Neurol. 2014;.

25. Bernard PB, Castano AM, Beitzel CS, Carlson VB, Benke TA. Behavioral changes following a single episode of early-life seizures support the latent development of an autistic phenotype. Epilepsy Behav. 2015;44:78-85.

26. Barnwell LF, Lugo JN, Lee WL, et al. Kv4.2 knockout mice demonstrate increased susceptibility to convulsant stimulation. Epilepsia. 2009;50:17411751.

27. Pellow S, Chopin P, File SE, Briley M. Validation of open:closed arm entries in an elevated plus-maze as a measure of anxiety in the rat. J Neurosci Methods. 1985;14:149-167.

28. Shimada T, Matsumoto K, Osanai M, Matsuda H, Terasawa K, Watanabe H. The modified light/dark transition test in mice: evaluation of classic and putative anxiolytic and anxiogenic drugs. Gen Pharmacol. 1995;26:205-210.

29. Spencer CM, Alekseyenko O, Serysheva E, Yuva-Paylor LA, Paylor R. Altered anxiety-related and social behaviors in the Fmr1 knockout mouse model of fragile X syndrome. Genes Brain Behav. 2005;4:420-430.

30. Mcllwain KL, Merriweather MY, Yuva-Paylor LA, Paylor R. The use of behaviora test batteries: effects of training history. Physiol Behav. 2001;73:705-717.
31. Bevins RA, Besheer J. Object recognition in rats and mice: a one-trial nonmatching-to-sample learning task to study 'recognition memory'. Nat Protoc. 2006; 1:1306-1311.

32. Swinkels WA, Kuyk J, de Graaf EH, van Dyck R, Spinhoven P. Prevalence of psychopathology in dutch epilepsy inpatients: a comparative study. Epilepsy Behav. 2001;2:441-447.

33. Ettinger AB, Weisbrot DM, Nolan EE, et al. Symptoms of depression and anxiety in pediatric epilepsy patients. Epilepsia. 1998;39:595-599.

34. Jones JE, Hermann BP, Barry JJ, Gilliam F, Kanner AM, Meador KJ. Clinical assessment of axis I psychiatric morbidity in chronic epilepsy: a multicenter investigation. J Neuropsychiatry Clin Neurosci. 2005;17:172-179.

35. Wahlsten D. Mouse behavioral testing: how to use mice in behavioral neuroscience. Mouse Behavioral Testing: How to Use Mice in Behavioral Neuroscience. : 1-288.

36. Boleij H, Salomons AR, van Sprundel M, Arndt SS, Ohl F. Not all mice are equal: welfare implications of behavioural habituation profiles in four 129 mouse substrains. PLoS One. 2012; 7:

37. Stafstrom CE. Assessing the behavioral and cognitive effects of seizures on the developing brain. Prog Brain Res. 2002;135:377-390.

38. Holmes GL, Tian C, Hernan AE, Flynn S, Camp D, Barry J. Alterations in sociability and functional brain connectivity caused by early-life seizures are prevented by bumetanide. Neurobiol Dis. 2015;77:204-219.

39. Canitano R. Epilepsy in autism spectrum disorders. Eur Child Adolesc Psychiatry. 2007; $16: 61-66$.

40. Tuchman R, Moshe SL, Rapin I. Convulsing toward the pathophysiology of autism. Brain Dev. 2009;31:95-103.

41. Karnam HB, Zhou JL, Huang LT, Zhao Q, Shatskikh T, Holmes GL. Early life seizures cause long-standing impairment of the hippocampal map. Exp Neurol. 2009;217:378-387.

42. Boyce R, Leung LS. Loss of dendritic inhibition in the hippocampus after repeated early-life hyperthermic seizures in rats. Epilepsy Res. 2013;103:62-

43. Nishimura M, Gu X, Swann JW. Seizures in early life suppress hippocampal dendrite growth while impairing spatial learning. Neurobiol Dis. 2011;44:205214.

44. Mumby DG. Perspectives on object-recognition memory following hippocampal damage: lessons from studies in rats. Behav Brain Res. 2001;127:159-181.

45. Ekinci O, Titus JB, Rodopman AA, Berkem M, Trevathan E. Depression and anxiety in children and adolescents with epilepsy: prevalence, risk factors, and treatment. Epilepsy Behav. 2009;14:8-18. 